\title{
When a good taste turns bad: Neural mechanisms underlying the emergence of negative affect and associated natural reward devaluation by cocaine
}

\author{
Regina M. Carelli ${ }^{1,2}$ and Elizabeth A. West ${ }^{1}$ \\ ${ }^{1}$ Department of Psychology, The University of North Carolina, Chapel Hill, Chapel Hill, NC 27599 \\ ${ }^{2}$ Neuroscience Center, The University of North Carolina, Chapel Hill, Chapel Hill, NC 27599
}

\section{Abstract}

An important feature of cocaine addiction in humans is the emergence of negative affect (e.g., dysphoria, irritability, anhedonia), postulated to play a key role in craving and relapse. Indeed, the DSM-IV recognizes that social, occupational and/or recreational activities become reduced as a consequence of repeated drug use where previously rewarding experiences (e.g., food, job, family) become devalued as the addict continues to seek and use drug despite serious negative consequences. Here, research in the Carelli laboratory is reviewed that examined neurobiological mechanisms that may underlie these processes using a novel animal model. Oromotor responses (taste reactivity) were examined as rats learned that intraoral infusion of a sweet (e.g., saccharin) predicts impending but delayed access to cocaine self-administration. We showed that rats exhibit aversive taste reactivity (i.e., gapes/rejection responses) during infusion of the sweet paired with impending cocaine, similar to aversive responses observed during infusion of quinine, a bitter tastant. Critically, the expression of this pronounced aversion to the sweet predicted the subsequent motivation to self-administer cocaine. Electrophysiology studies show that this shift in palatability corresponds to an alteration in nucleus accumbens (NAc) cell firing; neurons that previously responded with inhibition during infusion of the palatable sweet shifted to excitatory activity during infusion of the cocaine-devalued tastant. This excitatory response profile is typically observed during infusion of quinine, indicating that the once palatable sweet becomes aversive following its association with impending but delayed cocaine, and NAc neurons encode this aversive state. We also review electrochemical studies showing a shift (from increase to decrease) in rapid NAc dopamine release during infusion of the cocaine-paired tastant as the aversive state developed, again, resulting in responses similar to quinine infusion. Collectively, our findings suggest that cocaine-conditioned cues elicit a cocaine-need state that is aversive, is encoded by a distinct subset of NAc neurons and rapid dopamine signaling, and promotes cocaineseeking behavior. Finally, we present data showing that experimentally induced abstinence (30

\footnotetext{
(C) 2013 Elsevier Ltd. All rights reserved.

Corresponding author: Regina M. Carelli, Department of Psychology, CB \# 3270, Davie Hall, The University of North Carolina at Chapel Hill, Chapel Hill, NC 27599, rcarelli@unc.edu, Phone: 919-962-8775.

Publisher's Disclaimer: This is a PDF file of an unedited manuscript that has been accepted for publication. As a service to our customers we are providing this early version of the manuscript. The manuscript will undergo copyediting, typesetting, and review of the resulting proof before it is published in its final citable form. Please note that during the production process errors may be discovered which could affect the content, and all legal disclaimers that apply to the journal pertain.
} 
days) exacerbates this natural reward devaluation by cocaine, and this effect is correlated with a greater motivation to lever press during extinction. Dissecting the neural mechanisms underlying these detrimental consequences of addiction is critical since it may lead to novel treatments that ameliorate negative affective states associated with drug use and decrease the drive (craving) for the drug.

\section{Introduction}

Cocaine addiction is a complex disease characterized by cycles of drug consumption and abstinence followed by craving and relapse (Kalivas and Volkow, 2005; Koob and Volkow, 2010). Embedded in the addiction cycle is the well-established finding that natural rewards become devalued as a consequence of repeated drug use (American Psychiatric Association, 1993; Volkow et al., 2004). For example, friends, family, jobs and recreational activities become much less important to the addict in comparison to the drug. This occurs despite devastating consequences of continued drug use including alienation of friends and family, loss of employment and negative health consequences. Understanding the neurobiological mechanisms underlying natural reward devaluation by cocaine may be critically important when developing new behavioral and pharmacological treatments for addiction (Volkow et al., 2004).

A primary focus of research in the Carelli lab has been to understand neurobiological mechanisms mediating goal-directed actions for natural rewards (e.g., food/water) versus cocaine. We have directed our work at the nucleus accumbens (NAc) and its dopaminergic input given the unique anatomical arrangement of this structure and its role in 'limbic-motor integration' (Carelli and Wightman, 2004; Mogenson et al., 1980; Pennartz et al., 1994). Using electrophysiological recording procedures in behaving rats, we have shown that distinct subsets of NAc neurons selectively encode important features of goal-directed behaviors for cocaine versus natural rewards (Carelli and Deadwyler, 1994; Carelli et al., 2000; Carelli et al., 1993; Carelli and Wightman, 2004; Carelli and Wondolowski, 2003, 2006). Further, NAc neural activity, as well as rapid dopamine signaling in this structure, are highly dynamic and profoundly altered by a variety of factors including learning about stimuli associated with cocaine (Carelli, 2000, 2004), operant conditioning contingences (Carelli and Deadwyler, 1996; Carelli and Ijames, 2000, 2001; Carelli et al., 1993;

Hollander et al., 2002), as well as decision-making related to effort, delay (Day et al., 2011; Day et al., 2010) and risk-taking (Sugam and Carelli, 2013; Sugam et al., 2012). Additionally, neural activity in the NAc is dramatically altered by experimenter-controlled cocaine abstinence (Cameron and Carelli, 2012; Hollander and Carelli, 2005, 2007).

The dynamic nature of NAc signaling is also evident in our work that examined the role of the NAc in natural reward devaluation by cocaine. This interest was sparked by our early observations of behavioral profiles during tasks involving lever pressing for a natural reward (water or food) versus self-administered cocaine in a multiple schedule design. We noted that rats would stop lever pressing for the natural reward when that lever consistently preceded the drug lever (unpublished finding). This was a fascinating observation given the work by Grigson and others that showed that animals will respond less for a previously palatable natural reward when it comes to predict an abused drug (Grigson, 1997, 2000, 
2008; Grigson and Twining, 2002; Wise et al., 1976). Here, we review our work that examined a role of the NAc in natural reward devaluation by cocaine using a novel behavioral model in combination with electrophysiological and electrochemical approaches.

\section{An animal model of natural reward devaluation by cocaine}

In our initial study (Wheeler et al., 2008), rats where implanted with intraoral cannulae (for tastant infusion directly into their mouths), an intrajugular catheter for self-administration, and microelectrode arrays bilaterally positioned in the NAc core and shell. Our model was based on the finding that rats exhibit stereotyped oromotor responses, termed 'taste reactivity', to taste stimuli infused directly into the oral cavity that correspond to hedonic aspects of the stimulus (Grill and Norgren, 1978). Specifically, rats exhibit appetitive taste reactivity (e.g., licks) during infusion of a sweet tastant such as saccharin, and aversive taste reactivity (e.g., gapes) during intraoral infusion of a bitter tastant such as quinine. In our study, rats were given daily conditioning sessions completed in 2 phases. In the first phase, rats were intraorally infused with a distinctly flavored (e.g., orange) saccharin solution delivered over $3.5 \mathrm{~s}$ per trial every minute for 30 trials. In Phase 2, animals were trained to self-administer cocaine during daily 2 -hour sessions using established procedures. Lever depression on an FR1 schedule resulted in intravenous cocaine delivery $(0.33 \mathrm{mg} / \mathrm{inf}, 6 \mathrm{~s})$ that was signaled by termination of the cue light and simultaneous onset of a tone-houselight stimulus complex (20 s). The next day, the same rats underwent the same procedure with two changes: 1) the flavor of the saccharin solution was changed (e.g., from orange to grape) and 2) phase 2 involved self-administration of saline. This procedure was repeated for 14 days ( 7 of each pairing).

Using this design rats learned that infusion of a distinctly flavored tastant during phase 1 predicted the ability to self-administer cocaine in phase 2 . Inherent in this design however is that rats had to wait an extended period of time $(30 \mathrm{~min})$ to gain access to the drug. We hypothesized that the "drug waiting" period in phase 1 allowed for a strong association to develop between the tastant paired with delayed cocaine, and enabled the emergence of a negative affective state as measured by taste reactivity. In support, rats developed a strong aversion to the tastant that predicted cocaine (but not saline), reflected by changes in the oro-facial expression during tastant delivery. That is, the flavored saccharin solution paired with saline elicited classic appetitive taste reactivity (licking, lateral tongue protrusions; Fig. 1A (Wheeler et al., 2008). In contrast, the cocaine-paired tastant elicited aversive taste reactivity (gapes, Fig. 1B). This behavioral response profile was also reflected in EMG recordings of the anterior digastric muscle, a muscle coupled to licking (Fig 1C \& D).

Critically, the negative affective state that developed in phase 1 increased motivation to consume cocaine, once the drug was available in phase 2 . Specifically, aversive taste reactivity (gapes) was significantly correlated with cocaine loading responses (presses during the first $5 \mathrm{~min}$ of the session) and latency to the first press during cocaine selfadministration. That is, rats that exhibited the most gapes in phase 1 showed the greatest number of load up responses and the fastest latency to initiate responding for cocaine once the self-administration phase began (Fig. 1E). Following the final training day, rats were given a test session in which the unpaired (saline associated) then the paired (cocaine 
associated) tastants were intraorally infused. During the test session, rats exhibited primarily appetitive taste reactivity to the tastant associated with saline (unpaired) but aversive taste reactivity during infusion of the tastant predictive of cocaine (paired) (Fig. 1F). Further, rats preferred the tastant paired with saline over the one associated with cocaine in a two bottle test given following the test session. These findings are consistent with the view that a robust reversal of palatability occurs (from rewarding to aversive) for a tastant that predicts delayed cocaine availability, and that motivation for the drug increases following this shift.

\section{NAc neurons track the learned aversion to the sweet}

Under normal conditions, NAc neurons exhibit differential activity during direct application of palatable and unpalatable taste stimuli (Roitman et al., 2005; Wheeler and Carelli, 2009). Specifically, intraoral infusions of a palatable sucrose solution are associated, predominantly, with transiently reduced firing rates for NAc neurons. This response profile is illustrated in the perievent histogram $(\mathrm{PEH})$ and raster display for one NAc neuron in Fig. 2A. In contrast, NAc neurons exhibit predominantly excitatory responses during infusion of an aversive tastant, such as a bitter quinine solution, illustrated for another neuron in Fig. 2B. This differential pattern of neural activity cannot be attributed to goal-seeking (since the tastants were infused directly into the oral cavity), and therefore likely reflects the hedonic properties of the solutions.

Importantly, the aversive state that develops in our model of natural reward devaluation by cocaine is reflected in a shift in the activity of populations of NAc neurons. As noted above and illustrated in the pie charts in Fig. 3, under normal conditions the predominant response (approximately $75 \%$ ) of all phasically active NAc neurons to the application of a palatable taste stimulus is a reduction (inhibition) in firing rate (top left). Not surprisingly, a similar response profile was observed during infusion of the tastant paired with saline selfadministration in our model (bottom left). In contrast, the predominant neural response (approximately 75\%) to an unpalatable taste stimulus (quinine) is an increase (excitation) in activity (top right). A similar response profile was observed for the tastant paired with cocaine self-administration (bottom right). Further, the excitatory response profile and corresponding aversive taste reactivity were inversely correlated to the latency to make the first press for cocaine in the previous cocaine session. Collectively, these findings support the view that the switch in NAc activity to predominately excitatory during infusions of the cocaine-predictive tastant likely reflects the learned association with the drug, the development of the negative affective state, and increased motivation to consume cocaine once its available.

\section{Rapid Dopamine Signaling tracks the learned aversion to the sweet}

Next, we examined if the learned aversion to the sweet is also reflected in 'real time' dopamine release events (Wheeler et al., 2011). We used fast scan cyclic voltammetry (FSCV) to measure rapid dopamine (subsecond) release to a tastant that signaled delayed cocaine availability versus cues that signaled imminent cocaine. Although dopamine transmission does not directly mediate taste perception (Berridge and Robinson, 2003), electrophysiology studies show that dopamine activity rapidly increases in the NAc during 
the presentation of rewarding stimuli and typically decreases during aversive events (Mirenowicz and Schultz, 1996; Roitman et al., 2008; Ungless et al., 2004). In our first study, naive rats were implanted with intraoral catheters and one week later, given daily drug conditioning sessions. In each session, rats were intraorally infused with a grape or orange flavored saccharin solution, the paired tastant, delivered in $3.5 \mathrm{~s}$ trials for 45 trials. This was immediately followed by an investigator-delivered intraperitoneal (i.p.) injection of cocaine $(20 \mathrm{mg} / \mathrm{kg})$. The next day, the same rats were intraorally infused with the other flavored saccharin solution, the unpaired tastant that predicted an i.p. injection of saline. The rats received 10 taste-drug pairings. After training, all rats underwent surgery for FSCV and one week later they were tested while rapid dopamine signaling was measured. On the test day, rats were intraorally infused, with the unpaired and then the paired tastant in 45 discrete $3.5 \mathrm{~s}$ trials while orofacial responses (taste reactivity measures) were recorded. We showed that rapid dopamine release increased during infusion of the unpaired saccharin tastant (Fig $4 \mathrm{~A}$, open circles), but that this dopamine response profile was reversed (i.e., decrease in dopamine) during intraoral infusion of the cocaine-paired tastant (Fig. 4A, closed circles). As above, infusion of the paired cue was accompanied by classic aversive taste reactivity (Fig 4A, insert). This resembled the decline in NAc dopamine concentration (and expression of aversive taste reactivity) observed in naive animals during infusions of the bitter aversive stimulus, quinine (Fig. 4B; also see (Roitman et al., 2008).

Next, another set of rats were prepared with intraoral cannula, intrajugular catheters and voltammetric recordings in the NAc shell and following recovery, given daily drug conditioning sessions. In this case, rats were presented with an intraoral saccharin-sweetened solution delivered as above, across a 45 -min period before a 2 -hour cocaine self-

administration session. On the test day, behavioral responses and dopamine release events were recorded during taste presentation and self-administration. As predicted, the sweet taste associated with future cocaine availability induced a decrease in dopamine concentration (Fig 5A). Later in the same session, when rats had the opportunity to self-administer cocaine, an increase in dopamine concentration was observed immediately following the lever press, when animals received an audiovisual stimulus paired with cocaine (Fig 5B). We have previously shown that this pattern of dopamine release is related to the cocainepaired audiovisual stimulus (as opposed to a pharmacologic effect of the drug) and is sufficient to promote drug seeking (Phillips et al., 2003).

Clearly, the gustatory and audio/visual stimuli engage different sensory modalities. To control for this and to test the ability of a taste cue to differentially modulate dopamine release depending on its temporal relationship to cocaine availability, we ran an additional study in another set of rats. Rats were trained in a self-administration procedure in which the taste cue was not provided before cocaine-self administration, but as a replacement for the audiovisual cues that typically accompany a lever press for cocaine. In this case, dopamine was elevated following intraoral saccharin delivery examined in 'probe' trials before the self-administration phase (Fig. 5C), and dopamine was also elevated following the lever press that triggered both an intraoral saccharin infusion and intravenous cocaine infusion (Fig. 5D). Thus, we observed rapid and pronounced dopamine release for cues (either gustatory or audiovisual) that were associated with immediate cocaine delivery during selfadministration. These studies illustrate opposing dopaminergic release patterns (reduced 
when the taste cue predicts a delay to cocaine availability and elevated for taste cue/ audiovisual stimulus paired with cocaine delivery) related to the context in which the drug cues are given. This shift is neural signaling is consistent with previous studies that showed that NAc neurons and dopamine signaling track palatability shifts induced by a conditioned taste aversion or salt depletion (Loriaux et al., 2011; McCutcheon et al., 2012; Roitman et al., 2010).

\subsection{The learned taste-drug association is reflected in a dampening of the mesolimbic dopamine system}

Negative affect is a common symptom of drug addiction that is expressed across categories of abused substances (American Psychiatric Association, 1993; Baker et al., 2004) and this altered emotional state is thought to be the result of dysregulated mesolimbic dopamine function (Koob and Le Moal, 1997). We took two approaches in our study to examine if there is a generalized reduction in dopamine function in animals that learned the taste-drug association. Rapid dopamine signaling as measured by FSCV is increased during exposure to reward-associated stimuli (Phillips et al., 2003; Roitman et al., 2004). Increases in dopamine release events also occur intermittently during a session (i.e., not associated with a particular cue), a phenomena we have termed 'dopamine transients' (Wightman et al., 2007). Here, we examined dopamine transients between tastant infusions in phase 1. In a naive animal transient release events resulted in a stable time-averaged dopamine concentration plot that remained similar across all infusions (Fig 6A). However in an animal that learned the tastant predicted delayed cocaine, high-concentration transient release events were significantly reduced in later trials. This effect caused a reduced dopamine concentration for animals experiencing the cocaine-predictive taste, even when the tastant was not being infused (Fig 6B). This dampening of dopamine release coupled to aversive taste reactivity during tastant infusion is consistent with the emergence of a negative affective state (Koob and Le Moal, 1997).

Second, we employed the intracranial self-stimulation model (ICSS) to further confirm whether there is a generalized dampening of dopamine signaling in animals experiencing the negative affective state in our model. ICSS serves as a broad measure of reward function with pronounced decreases in reward sensitivity (detected as elevations in reward threshold) following withdrawal from abused substances (Carlezon and Chartoff, 2007; Koob and Le Moal, 1997). We hypothesized that if the cocaine-predictive taste cue, presented across an extended time period, is eliciting a negative affective state, then rats would also demonstrate reduced ICSS sensitivity. Using our model, rats trained with a taste cue presented $45 \mathrm{~min}$ before cocaine availability then were subsequently trained to press a distinct lever for ICSS across several days. After training, rats pressed the lever for a descending range of ICSS frequencies. After establishing baseline frequency responses, the cocaine-predictive tastant was given, as previously, and the response rates for descending stimulus frequencies were again recorded. As shown in Fig 6C, we observed a significant rightward shift in the frequency response curve, demonstrating an elevated ICSS threshold. This shift was not observed the following day when rats were exposed to water (Fig. 6D). Collectively, these findings indicate a pronounced dampening of the dopamine system during exposure to the cue that signaled impending, but delayed cocaine availability. 


\section{Negative Affective State \& Conditioned Withdrawal}

We hypothesize that the increased motivated behavior for cocaine following this learned association may be a consequence of the development of a negative affective state that is a consequence of delayed drug availability. As postulated by Koob and colleagues, chronic cocaine self-administration alters the rat's 'hedonic set point', reducing responsiveness to rewarding stimuli (Ahmed and Koob, 1998). As a modified form of the opponent process theory (Solomon and Corbit, 1974), it is thought that this allosteric regulation reduces the hedonic set point by increasing the function of "antireward" brain systems, thereby increasing tolerance to the hedonic effects of cocaine (Ahmed and Koob, 1998, 2005; Koob et al., 2004). This negative state is thought to be alleviated by drug loading (a phenomenon observed our model in rats that show pronounced aversion to the cocaine-associated taste). Our findings, consistent with this model, provide compelling evidence that the tastant that predicts impending but delayed cocaine availability induces a conditioned negative affective state that is reflected in the activity of distinct subsets of NAc neurons (Wheeler and Carelli, 2009; Wheeler et al., 2008) and rapid DA release (Wheeler et al., 2011), and is corrected by cocaine self-administration. Thus, during this drug 'waiting period', we postulate that the rat experiences an aversive state that may include the onset of conditioned anxiety, craving (a strong subjective drive to use the drug), and/or withdrawal (i.e., a cocaine-need state).

Indeed, a recent report by Grigson and colleagues provided direct evidence that a drugpaired taste cue elicits withdrawal and predicts cocaine self-administration in rats (Nyland and Grigson, 2013). In their study a saccharin taste cue was paired with the opportunity to self-administer cocaine. After 7 days of taste-drug pairings, rats received the cocaineassociated taste cue in the self-administration chambers followed by an injection of naloxone. Naloxone can precipitate measurable indices of withdrawal, including a decrease in body weight. As such, the authors very cleverly examined body weight loss to test if a drug-paired taste cue elicits conditioned withdrawal in anticipation of drug availability. The authors report the cocaine group had a significant loss in body weight $2 \mathrm{~h}$ after naloxone administration and greater withdrawal predicted greater cocaine self-administration in rats. These findings are consistent with the notion that avoidance of the drug-paired taste cue may result from the development of an aversive conditioned state of withdrawal that develops when the taste cue comes to predict the delayed availability of drug.

\section{Heightened Aversive State following Cocaine Abstinence}

In humans, drug taking behavior is typically followed by periods of abstinence from drug use then increased drug consumption (Gawin, 1991). In animal models, removal of the abused substance (i.e., experimenter controlled abstinence, also referred to as withdrawal) results in numerous 'neuroadaptations' in the brain reward system. For example, reports indicate glutamate-related cellular changes (Baker et al., 2003; Ghasemzadeh et al., 2003; Kalivas et al., 2003), alterations in gene expression (Toda et al., 2002), alterations in GABA concentration (Xi et al., 2003), and structural changes in NAc medium spiny neurons (Robinson et al., 2001; Robinson and Kolb, 2004) following cocaine removal. Further, onemonth abstinence from cocaine self-administration results in changes in cAMP dependent protein kinase, adenylate cyclase, tyrosine hydroxylase and alterations in various glutamate 
receptor subunits in the VTA and/or NAc (Lu et al., 2003). Abstinence from cocaine selfadministration induces an "incubation of craving" effect whereby rats exhibit enhanced responding during extinction following experimenter-imposed abstinence (Lu et al., 2004; Pickens et al., 2011). Formation of GluA2-lacking AMPAs in NAc neurons following prolonged cocaine abstinence appears to mediate this enhanced cocaine-seeking (Conrad et al., 2008). Importantly, neuroplasticity associated with drug use is modulated by dopamine (Berke and Hyman, 2000; Hyman et al., 2006; Pickens et al., 2011), and changes in the dopamine system are observed in nonhuman primates (Beveridge et al., 2009; Nader et al., 2006) and humans (Volkow et al., 1997) following cocaine abstinence.

Electrophysiological recordings in behaving rats have also revealed discrete changes in NAc signaling following experimenter-controlled abstinence. For example, we reported that interruption of cocaine access following self-administration caused a dramatic increase in the number and strength of NAc neurons that encode cocaine-related information (Hollander and Carelli, 2005), a heightened activation of NAc neurons by cocaine-associated stimuli (Hollander and Carelli, 2007), and enhanced drug seeking during extinction that was encoded by distinct populations of NAc neurons (Cameron and Carelli, 2012; Hollander and Carelli, 2007). We also reported a shift in neural signaling toward more cocaine-related processing (as opposed to food) following abstinence that may be relevant to the decrease in reinforcing properties of natural rewards reported by human drug addicts (Gawin, 1991; Grigson, 2008). Critically, Grigson and Twining (2002) showed that following 1-month cocaine abstinence the devaluation of a natural reward by cocaine was maintained, and that abstinence exacerbated drug seeking during extinction (i.e., incubation of craving).

These findings indicate that the learned aversive state that occurs when the sweet signals impending, but delayed drug availability is maintained during withdrawal and prolonged abstinence. Recent research in our laboratory (unpublished) confirms and extends those findings. Rats were prepared for intra-oral cannula and intrajugular catheters and trained on our natural reward devaluation task. In phase 1 , all rats were intra-orally infused with a flavored saccharin solution in $3.5 \mathrm{~s}$ trials every min for 45 trials. Immediately after in phase 2 , rats were able to self-administer cocaine using procedures described above. Animals were trained for 14 days. Taste reactivity was measured on day 1 of training, day 14 of training and following 30 days of experimenter controlled cocaine abstinence $(n=5)$. There was a significant change in taste reactivity across days for both aversive and appetitive responses $\left(F_{2,3}=57.3 ; p<0.01 ; F_{2,3}=12.4 ; p<0.01\right.$, respectively). As indicated in Fig. 7 , on day 1, rats exhibited primarily appetitive taste reactivity during tastant infusion (Fig. 7A\&B, left columns). This behavioral profile shifted to predominately aversive taste reactivity following 14 days of training (Fig. 7A\&B, middle columns). Importantly, this aversive state was amplified following 1 month cocaine abstinence reflected by significantly more aversive counts $(t=5.9, \mathrm{p}<0.01)$ and a trend towards fewer appetitive counts $(t=2.4, \mathrm{p}=0.08$; Fig 7. A\&B, right columns). Consistent with an incubation of craving effect, the same rats exhibited significantly increased lever pressing during extinction, compared to another group of rats $(n=4)$ that experienced only 1 day cocaine abstinence $(t=3.1818, p<0.05$; Fig. 7C). Finally, we found a significant positive correlation between the number of lever presses during extinction and the percent change in aversive taste reactivity following abstinence 
(Fig. 7D). These findings indicate that the larger the number of lever press responses during extinction, the greater the expression of aversive taste reactivity.

\section{Beyond the NAc: Possible Neural Circuit underlying Natural Reward Devaluation by Cocaine}

To date, our work has focused exclusively on the role of the NAc in natural reward devaluation by cocaine. Since the NAc does not function in isolation but is embedded in a larger neural circuit, it will be important to determine other neural substrates involved in this process. In this regard, neural regions attributed to stress processing (Koob et al., 2004; Koob and Zorrilla, 2010) and withdrawal/aversion (Koob and Volkow, 2010) are likely candidates, particularly since the stress circuit has been implicated in stages of drug addiction, craving and relapse (Koob and Volkow, 2010; Koob and Zorrilla, 2010; Sinha et al., 2003; Preston and Epstein, 2011). Further, in rats, the stress hormone, corticosterone, is elevated to a taste cue that signals a delay in drug delivery (Gomez et al., 2000) possibly reflecting a negative affective state.

One brain region of interest for its role in stress and addiction and its anatomical link to the NAc as part of the 'extended amygdala' is the bed nucleus stria terminalis (BNST). The BNST integrates information between limbic structures (e.g., amygdala and medial prefrontal cortex) and the hypothalamic paraventricular nucleus (PVN), and is therefore well-positioned to play a role in modulating reward, aversion and stress (Erb and Stewart, 1999; McFarland et al., 2004; Wenzel et al., 2011). We used FSCV to measure 'real time' changes in extracellular catecholamine concentration during intra oral delivery of either sucrose or quinine in distinct subregions of the BNST (Park et al., 2012). The BNST is divided into several anatomically distinct regions including two which are neurochemically distinct, the dorsolateral ( $d l \mathrm{BNST}$ ) and ventral ( $v$ BNST). The $v$ BNST receives dense norepinephrine (NE) innervation from the nucleus of solitary tract and locus coeruleus, but little dopamine input (Delfs et al., 2000; Park et al., 2009). In contrast, the dlBNST receives dopamine innervation from the ventral tegmental area (VTA), but contains little norepinephrine (Hasue and Shammah-Lagnado, 2002; Meloni et al., 2006). We found that the aversive stimulus quinine activated NE signaling in vBNST but inhibited dopamine release in the dIBNST, whereas the palatable stimulus, sucrose, had the opposite effect, inhibiting NE in vBNST and causing dopamine release in the dIBNST. We speculate that the net result of these reciprocal neurochemical actions is an excitation of the HPA axis in response to aversive stimuli and an inhibition in response to rewarding stimuli. Our data are consistent with the view that the BNST functions as a reward-aversion integrator, processing opposing hedonic states and influencing response outputs appropriate for survival. These findings suggests that BNST-NAc circuit may be a prime candidate to modulate the shift in hedonic value of a natural reward, and increases in stress associated withdrawal (Gomez et al., 2000; Nyland and Grigson, 2012), after it predicts delayed cocaine availability.

A number of other neural substrates could also be involved in the negative affective state in our model. For example, the amygdala has been implicated in the regulation of emotional memory (LeDoux, 2003) and associative learning (Holland and Gallagher 1999) and thus may play a role in this process. The basolateral amygdala (BLA), which sends dense 
projections to NAc (Kelley et al., 1982), influences discrete aspects of NAc activity and dopamine release during goal-directed behaviors (Carelli et al., 2003; Jones et al., 2010a; Jones et al., 2010b; Jones et al., 2008). Further, the BLA is necessary for updating associations about motivational stimuli to reflect changes in reward value (Balleine et al., 2003; Hatfield et al., 1996; West et al., 2012). Importantly, the amygdala has also been implicated in drug addiction in animals (Beveridge et al., 2006; See et al., 2003) and human addicts (Childress et al., 1999; Makris et al., 2004). Likewise, the medial prefrontal cortex $(\mathrm{mPFC})$ is of interest. Rats that show persistent compulsive drug seeking exhibit changes in mPFC excitability (Chen et al., 2013). Further, enhancement of mPFC activity is sufficient to induce incubation of craving in rats after only one day of abstinence (Koya et al., 2009). Finally, the LHb is another important region to consider since activation of LHb efferents to the midbrain produces aversion (Stamatakis and Stuber, 2012). Further, LHb neurons preferentially synapse on VTA dopamine neurons that project to the medial PFC (Lammel et al., 2012), which are preferentially activated by aversive stimuli (Lammel et al., 2012). In sum, the NAc is likely part of a larger complex neural network influencing/controlling the negative affective state revealed in our model.

\section{Concluding remarks}

Numerous studies have examined three key factors that appear to play critical roles in driving drug relapse: the drug itself, stress and cocaine-associated cues (Gawin, 1991; O'Brien et al., 1992). However embedded in the addiction cycle is the emergence of negative affective states including dysphoria, irritability, and anhedonia that appear equally important (Baker et al., 2004; Fox et al., 2008; Koob and Le Moal, 1997; Newton et al., 2003). We hypothesize that the cocaine-paired taste in our model serves as a predictive cue of cocaine's impending availability and precipitates the expression of a conditioned aversive state in learned anticipation of the future opportunity to self-administer cocaine [see (Wheeler et al., 2008)]. The critical feature of our model is that the rat has to 'wait' an extended period for drug availability, and this waiting period is aversive (as revealed by gapes during infusion of the previously palatable tastant). Indeed, aversive taste reactivity was not observed by Parker and colleagues when cocaine immediately followed tastant infusion (Parker, 1995). Said another way, our model may be analogous to placing an addict in a room, and telling him/her that they can have all the cocaine they desire - but they have to wait to gain access to it. During this waiting period the addict (in our model, rat) experiences an aversive state that may include the onset of conditioned anxiety, craving (a strong subjective drive to use the drug), and/or withdrawal (i.e., a cocaine-need state). Further, once in this state, interest in other previously rewarding items (e.g., food, family, friends) pales in comparison to their desire for drug (American Psyhiatric Association, 1993; Dackis, 2004; Santolaria-Fernandez et al., 1995) and these negative feelings play an important role in craving and relapse (Koob and Volkow, 2010). Critically, this negative affective state is 'corrected' by the drug itself. Indeed, we showed that rats exhibiting the strongest aversive taste reactivity were the most motivated to consume the drug, once available (Wheeler et al., 2008). Further, this aversive state is exacerbated following prolonged cocaine abstinence [(Grigson and Twining, 2002) and Fig. 7], and is observed with other abused substances (Parker, 1995; Gomez et at al., 2000; Grigson, 2008; Nyland 
and Grigson, 2013). Thus, understanding the neurobiological mechanisms mediating the emergence of negative affective states and associated devaluation of natural rewards by cocaine could led to novel pharmacological treatments that ameliorate this detrimental consequence of repeated drug use, help refocus the addicts interest toward natural reward procurement, and attenuate the continued drive (craving) for the drug.

\section{Acknowledgments}

This work was supported by DA017318 and DA014339 to RMC.

\section{References}

Ahmed SH, Koob GF. Transition from moderate to excessive drug intake: change in hedonic set point. Science. 1998; 282:298-300. [PubMed: 9765157]

Ahmed SH, Koob GF. Transition to drug addiction: a negative reinforcement model based on an allostatic decrease in reward function. Psychopharmacology (Berl). 2005; 180:473-490. [PubMed: 15731896]

American Psychiatric Association, A. P. Diagnostic and Statistical Manual of Mental Disorders. 4. Washington, DC: American Psychiatric Publishing; 1993.

Baker DA, McFarland K, Lake RW, Shen H, Tang XC, Toda S, Kalivas PW. Neuroadaptations in cystine-glutamate exchange underlie cocaine relapse. Nat Neurosci. 2003; 6:743-749. [PubMed: 12778052]

Baker TB, Piper ME, McCarthy DE, Majeskie MR, Fiore MC. Addiction motivation reformulated: an affective processing model of negative reinforcement. Psychol Rev. 2004; 111:33-51. [PubMed: 14756584]

Balleine BW, Killcross AS, Dickinson A. The effect of lesions of the basolateral amygdala on instrumental conditioning. J Neurosci. 2003; 23:666-675. [PubMed: 12533626]

Berke JD, Hyman SE. Addiction, dopamine, and the molecular mechanisms of memory. Neuron. 2000; 25:515-532. [PubMed: 10774721]

Berridge KC, Robinson TE. Parsing reward. Trends Neurosci. 2003; 26:507-513. [PubMed: 12948663]

Beveridge TJ, Smith HR, Nader MA, Porrino LJ. Abstinence from chronic cocaine self-administration alters striatal dopamine systems in rhesus monkeys. Neuropsychopharmacology. 2009; 34:11621171. [PubMed: 18769473]

Beveridge TJ, Smith HR, Daunais JB, Nader MA, Porrino LJ. Chronic cocaine self-administration is associated with altered functional activity in the temporal lobes of non human primates. Eur $\mathbf{J}$ Neurosci. 2006; 23:3109-3118. [PubMed: 16820001]

Cameron CM, Carelli RM. Cocaine abstinence alters nucleus accumbens firing dynamics during goaldirected behaviors for cocaine and sucrose. Eur J Neurosci. 2012; 35:940-951. [PubMed: 22356698]

Carelli RM. Activation of accumbens cell firing by stimuli associated with cocaine delivery during self-administration. Synapse. 2000; 35:238-242. [PubMed: 10657032]

Carelli RM. Nucleus accumbens cell firing and rapid dopamine signaling during goal- directed behaviors in rats. Neuropharmacology. 2004; 47(Suppl 1):180-189. [PubMed: 15464136]

Carelli RM, Deadwyler SA. A comparison of nucleus accumbens neuronal firing patterns during cocaine self-administration and water reinforcement in rats. J Neurosci. 1994; 14:7735-7746. [PubMed: 7996208]

Carelli RM, Deadwyler SA. Dual factors controlling activity of nucleus accumbens cell-firing during cocaine self-administration. Synapse. 1996; 24:308-311. [PubMed: 8923672]

Carelli RM, Ijames SG. Nucleus accumbens cell firing during maintenance, extinction, and reinstatement of cocaine self-administration behavior in rats. Brain Res. 2000; 866:44-54. [PubMed: 10825479] 
Carelli RM, Ijames SG. Selective activation of accumbens neurons by cocaine- associated stimuli during a water/cocaine multiple schedule. Brain Res. 2001; 907:156-161. [PubMed: 11430899]

Carelli RM, Ijames SG, Crumling AJ. Evidence that separate neural circuits in the nucleus accumbens encode cocaine versus "natural" (water and food) reward. J Neurosci. 2000; 20:4255-4266. [PubMed: 10818162]

Carelli RM, King VC, Hampson RE, Deadwyler SA. Firing patterns of nucleus accumbens neurons during cocaine self-administration in rats. Brain Res. 1993; 626:14-22. [PubMed: 8281424]

Carelli RM, Wightman RM. Functional microcircuitry in the accumbens underlying drug addiction: insights from real-time signaling during behavior. Curr Opin Neurobiol. 2004; 14:763-768. [PubMed: 15582381]

Carelli RM, Williams JG, Hollander JA. Basolateral amygdala neurons encode cocaine selfadministration and cocaine-associated cues. J Neurosci. 2003; 23:8204-8211. [PubMed: 12967981]

Carelli RM, Wondolowski J. Selective encoding of cocaine versus natural rewards by nucleus accumbens neurons is not related to chronic drug exposure. J Neurosci. 2003; 23:11214-11223. [PubMed: 14657180]

Carelli RM, Wondolowski J. Anatomic distribution of reinforcer selective cell firing in the core and shell of the nucleus accumbens. Synapse. 2006; 59:69-73. [PubMed: 16270303]

Carlezon WA Jr, Chartoff EH. Intracranial self-stimulation (ICSS) in rodents to study the neurobiology of motivation. Nat Protoc. 2007; 2:2987-2995. [PubMed: 18007634]

Chen BT, Yau H, Hatch C, Kusomoto-Yoshida I, Cho SL, Hopf FW, Bonci A. Rescuing cocaineinduced prefrontal cortex hypoactivity prevents compulsive cocaine seeking. Nature. 2013 In press.

Childress AR, Mozley PD, McElgin W, Fitzgerald J, Reivich M, O’Brien CP. Limbic activation during cue-induced cocaine craving. Am J Psychiatry. 1999; 156:11-18. [PubMed: 9892292]

Conrad KL, Tseng KY, Uejima JL, Reimers JM, Heng LJ, Shaham Y, Marinelli M, Wolf ME. Formation of accumbens GluR2-lacking AMPA receptors mediates incubation of cocaine craving. Nature. 2008; 454:118-121. [PubMed: 18500330]

Dackis CA. Recent advances in the pharmacotherapy of cocaine dependence. Curr Psychiatry Rep. 2004; 6:323-331. [PubMed: 15355754]

Day JJ, Jones JL, Carelli RM. Nucleus accumbens neurons encode predicted and ongoing reward costs in rats. Eur J Neurosci. 2011; 33:308-321. [PubMed: 21198983]

Day JJ, Jones JL, Wightman RM, Carelli RM. Phasic nucleus accumbens dopamine release encodes effort- and delay-related costs. Biol Psychiatry. 2010; 68:306-309. [PubMed: 20452572]

Delfs JM, Zhu Y, Druhan JP, Aston-Jones G. Noradrenaline in the ventral forebrain is critical for opiate withdrawal-induced aversion. Nature. 2000; 403:430-434. [PubMed: 10667795]

Erb S, Stewart J. A role for the bed nucleus of the stria terminalis, but not the amygdala, in the effects of corticotropin-releasing factor on stress-induced reinstatement of cocaine seeking. J Neurosci. 1999; 19:RC35. [PubMed: 10516337]

Fox HC, Hong KI, Siedlarz K, Sinha R. Enhanced sensitivity to stress and drug/alcohol craving in abstinent cocaine-dependent individuals compared to social drinkers. Neuropsychopharmacology. 2008; 33:796-805. [PubMed: 17568398]

Gawin FH. Cocaine addiction: psychology and neurophysiology. Science. 1991; 251:1580-1586. [PubMed: 2011738]

Ghasemzadeh MB, Permenter LK, Lake R, Worley PF, Kalivas PW. Homer1 proteins and AMPA receptors modulate cocaine-induced behavioural plasticity. Eur J Neurosci. 2003; 18:1645-1651. [PubMed: 14511343]

Gomez F, Leo NA, Grigson PS. Morphine-induced suppression of saccharin intake is correlated with elevated corticosterone levels. Brain Res. 2000; 863:52-58. [PubMed: 10773192]

Grigson PS. Conditioned taste aversions and drugs of abuse: a reinterpretation. Behav Neurosci. 1997; 111:129-136. [PubMed: 9109631]

Grigson PS. Drugs of abuse and reward comparison: a brief review. Appetite. 2000; 35:89-91. [PubMed: 10896765] 
Grigson PS. Reward Comparison: The Achilles' heel and hope for addiction. Drug Discov Today Dis Models. 2008; 5:227-233. [PubMed: 20016772]

Grigson PS, Twining RC. Cocaine-induced suppression of saccharin intake: a model of drug-induced devaluation of natural rewards. Behav Neurosci. 2002; 116:321-333. [PubMed: 11996317]

Grill HJ, Norgren R. The taste reactivity test. I. Mimetic responses to gustatory stimuli in neurologically normal rats. Brain Res. 1978; 143:263-279. [PubMed: 630409]

Hasue RH, Shammah-Lagnado SJ. Origin of the dopaminergic innervation of the central extended amygdala and accumbens shell: a combined retrograde tracing and immunohistochemical study in the rat. J Comp Neurol. 2002; 454:15-33. [PubMed: 12410615]

Hatfield T, Han JS, Conley M, Gallagher M, Holland P. Neurotoxic lesions of basolateral, but not central, amygdala interfere with Pavlovian second-order conditioning and reinforcer devaluation effects. J Neurosci. 1996; 16:5256-5265. [PubMed: 8756453]

Holland PC, Gallagher M. Amygdala circuitry in attentional and representational processes. Trends Cogn Sci. 1999; 3(2):65-73. [PubMed: 10234229]

Hollander JA, Carelli RM. Abstinence from cocaine self-administration heightens neural encoding of goal-directed behaviors in the accumbens. Neuropsychopharmacology. 2005; 30:1464-1474. [PubMed: 15856078]

Hollander JA, Carelli RM. Cocaine-associated stimuli increase cocaine seeking and activate accumbens core neurons after abstinence. J Neurosci. 2007; 27:3535-3539. [PubMed: 17392469]

Hollander JA, Ijames SG, Roop RG, Carelli RM. An examination of nucleus accumbens cell firing during extinction and reinstatement of water reinforcement behavior in rats. Brain Res. 2002; 929:226-235. [PubMed: 11864628]

Hyman SE, Malenka RC, Nestler EJ. Neural mechanisms of addiction: the role of reward-related learning and memory. Annu Rev Neurosci. 2006; 29:565-598. [PubMed: 16776597]

Jones JL, Day JJ, Aragona BJ, Wheeler RA, Wightman RM, Carelli RM. Basolateral amygdala modulates terminal dopamine release in the nucleus accumbens and conditioned responding. Biol Psychiatry. 2010a; 67:737-744. [PubMed: 20044074]

Jones JL, Day JJ, Wheeler RA, Carelli RM. The basolateral amygdala differentially regulates conditioned neural responses within the nucleus accumbens core and shell. Neuroscience. 2010b; 169:1186-1198. [PubMed: 20570714]

Jones JL, Wheeler RA, Carelli RM. Behavioral responding and nucleus accumbens cell firing are unaltered following periods of abstinence from sucrose. Synapse. 2008; 62:219-228. [PubMed: 18088061]

Kalivas PW, McFarland K, Bowers S, Szumlinski K, Xi ZX, Baker D. Glutamate transmission and addiction to cocaine. Ann N Y Acad Sci. 2003; 1003:169-175. [PubMed: 14684444]

Kalivas PW, Volkow ND. The neural basis of addiction: a pathology of motivation and choice. Am J Psychiatry. 2005; 162:1403-1413. [PubMed: 16055761]

Kelley AE, Domesick VB, Nauta WJ. The amygdalostriatal projection in the rat--an anatomical study by anterograde and retrograde tracing methods. Neuroscience. 1982; 7(3):615-30. [PubMed: 7070669]

Koob GF, Ahmed SH, Boutrel B, Chen SA, Kenny PJ, Markou A, O’Dell LE, Parsons LH, Sanna PP. Neurobiological mechanisms in the transition from drug use to drug dependence. Neurosci Biobehav Rev. 2004; 27:739-749. [PubMed: 15019424]

Koob GF, Le Moal M. Drug abuse: hedonic homeostatic dysregulation. Science. 1997; 278:52-58. [PubMed: 9311926]

Koob GF, Volkow ND. Neurocircuitry of addiction. Neuropsychopharmacology. 2010; 35:217-238. [PubMed: 19710631]

Koob GF, Zorrilla EP. Neurobiological mechanisms of addiction: focus on corticotropin-releasing factor. Curr Opin Investig Drugs. 2010; 11:63-71.

Koya E, Uejima JL, Wihbey KA, Bossert JM, Hope BT, Shaham Y. Role of ventral medial prefrontal cortex in incubation of cocaine craving. Neuropharmacology. 2009; 56(Suppl 1):177-185.

[PubMed: 18565549] 
Lammel S, Lim BK, Ran C, Huang KW, Betley MJ, Tye KM, Deisseroth K, Malenka RC. Inputspecific control of reward and aversion in the ventral tegmental area. Nature. 2012; 491:212-217. [PubMed: 23064228]

LeDoux J. The emotional brain, fear and the amygdala. Cell Mol Neurobiol. 2003; 23(4-5):727-38. [PubMed: 14514027]

Loriaux AL, Roitman JD, Roitman MF. Nucleus accumbens shell, but not core, tracks motivational value of salt. J Neurophysiol. 2011; 106:1537-1544. [PubMed: 21697439]

Lu L, Grimm JW, Hope BT, Shaham Y. Incubation of cocaine craving after withdrawal: a review of preclinical data. Neuropharmacology. 2004; 47(Suppl 1):214-226. [PubMed: 15464139]

Lu L, Grimm JW, Shaham Y, Hope BT. Molecular neuroadaptations in the accumbens and ventral tegmental area during the first 90 days of forced abstinence from cocaine self-administration in rats. J Neurochem. 2003; 85:1604-1613. [PubMed: 12787079]

Makris N, Gasic GP, Seidman LJ, Goldstein JM, Gastfriend DR, Elman I, Albaugh MD, Hodge SM, Ziegler DA, Sheahan FS, Caviness VS Jr, Tsuang MT, Kennedy DN, Hyman SE, Rosen BR, Breiter HC. Decreased absolute amygdala volume in cocaine addicts. Neuron. 2004; 44:729-740. [PubMed: 15541319]

McCutcheon JE, Ebner SR, Loriaux AL, Roitman MF. Encoding of aversion by dopamine and the nucleus accumbens. Front Neurosci. 2012; 6:137. [PubMed: 23055953]

McFarland K, Davidge SB, Lapish CC, Kalivas PW. Limbic and motor circuitry underlying footshockinduced reinstatement of cocaine-seeking behavior. J Neurosci. 2004; 24:1551-1560. [PubMed: 14973230]

Meloni EG, Gerety LP, Knoll AT, Cohen BM, Carlezon WA Jr. Behavioral and anatomical interactions between dopamine and corticotropin-releasing factor in the rat. J Neurosci. 2006; 26:3855-3863. [PubMed: 16597740]

Mirenowicz J, Schultz W. Preferential activation of midbrain dopamine neurons by appetitive rather than aversive stimuli. Nature. 1996; 379:449-451. [PubMed: 8559249]

Mogenson GJ, Jones DL, Yim CY. From motivation to action: functional interface between the limbic system and the motor system. Prog Neurobiol. 1980; 14:69-97. [PubMed: 6999537]

Nader MA, Morgan D, Gage HD, Nader SH, Calhoun TL, Buchheimer N, Ehrenkaufer R, Mach RH. PET imaging of dopamine D2 receptors during chronic cocaine self-administration in monkeys. Nat Neurosci. 2006; 9:1050-1056. [PubMed: 16829955]

Newton TF, Kalechstein AD, Tervo KE, Ling W. Irritability following abstinence from cocaine predicts euphoric effects of cocaine administration. Addict Behav. 2003; 28:817-821. [PubMed: 12726795]

Nyland JE, Grigson PS. A drug-paired taste cue elicits withdrawal and predicts cocaine selfadministration. Behav Brain Res. 2013; 240:87-90. [PubMed: 23174208]

O'Brien CP, Childress AR, McLellan AT, Ehrman R. Classical conditioning in drug-dependent humans. Ann N Y Acad Sci. 1992; 654:400-415. [PubMed: 1632593]

Park J, Wheeler RA, Fontillas K, Keithley RB, Carelli RM, Wightman RM. Catecholamines in the bed nucleus of the stria terminalis reciprocally respond to reward and aversion. Biol Psychiatry. 2012; 71(4):327-34. [PubMed: 22115620]

Park J, Kile BM, Wightman RM. In vivo voltammetric monitoring of norepinephrine release in the rat ventral bed nucleus of the stria terminalis and anteroventral thalamic nucleus. Eur J Neurosci. 2009; 30:2121-2133. [PubMed: 20128849]

Parker LA. Rewarding drugs produce taste avoidance, but not taste aversion. Neurosci Biobehav Rev. 1995; 19:143-157. [PubMed: 7770194]

Pennartz CM, Groenewegen HJ, Lopes da Silva FH. The nucleus accumbens as a complex of functionally distinct neuronal ensembles: an integration of behavioural, electrophysiological and anatomical data. Prog Neurobiol. 1994; 42:719-761. [PubMed: 7938546]

Phillips PE, Stuber GD, Heien ML, Wightman RM, Carelli RM. Subsecond dopamine release promotes cocaine seeking. Nature. 2003; 422:614-618. [PubMed: 12687000]

Pickens CL, Airavaara M, Theberge F, Fanous S, Hope BT, Shaham Y. Neurobiology of the incubation of drug craving. Trends Neurosci. 2011; 34:411-420. [PubMed: 21764143] 
Preston KL, Epstein DH. Stress in the daily lives of cocaine and heroin users: relationship to mood, craving, relapse triggers, and cocaine use. Psychopharmacology (Berl). 2011; 218:29-37. [PubMed: 21336579]

Robinson TE, Gorny G, Mitton E, Kolb B. Cocaine self-administration alters the morphology of dendrites and dendritic spines in the nucleus accumbens and neocortex. Synapse. 2001; 39:257266. [PubMed: 11169774]

Robinson TE, Kolb B. Structural plasticity associated with exposure to drugs of abuse. Neuropharmacology. 2004; 47(Suppl 1):33-46. [PubMed: 15464124]

Roitman MF, Stuber GD, Phillips PE, Wightman RM, Carelli RM. Dopamine operates as a subsecond modulator of food seeking. J Neurosci. 2004; 24:1265-1271. [PubMed: 14960596]

Roitman MF, Wheeler RA, Carelli RM. Nucleus accumbens neurons are innately tuned for rewarding and aversive taste stimuli, encode their predictors, and are linked to motor output. Neuron. 2005; 45:587-597. [PubMed: 15721244]

Roitman MF, Wheeler RA, Tiesinga PH, Roitman JD, Carelli RM. Hedonic and nucleus accumbens neural responses to a natural reward are regulated by aversive conditioning. Learn Mem. 2010; 17:539-546. [PubMed: 20971936]

Roitman MF, Wheeler RA, Wightman RM, Carelli RM. Real-time chemical responses in the nucleus accumbens differentiate rewarding and aversive stimuli. Nat Neurosci. 2008; 11:1376-1377. [PubMed: 18978779]

Santolaria-Fernandez FJ, Gomez-Sirvent JL, Gonzalez-Reimers CE, Batista-Lopez JN, JorgeHernandez JA, Rodriguez-Moreno F, Martinez-Riera A, Hernandez-Garcia MT. Nutritional assessment of drug addicts. Drug Alcohol Depend. 1995; 38:11-18. [PubMed: 7648992]

See RE, Fuchs RA, Ledford CC, McLaughlin J. Drug addiction, relapse, and the amygdala. Ann N Y Acad Sci. 2003; 985:294-307. [PubMed: 12724166]

Sinha R, Talih M, Malison R, Cooney N, Anderson GM, Kreek MJ. Hypothalamic-pituitary-adrenal axis and sympatho-adreno-medullary responses during stress-induced and drug cue-induced cocaine craving states. Psychopharmacology (Berl). 2003; 170:62-72. [PubMed: 12845411]

Solomon RL, Corbit JD. An opponent-process theory of motivation. I. Temporal dynamics of affect. Psychol Rev. 1974; 81:119-145. [PubMed: 4817611]

Stamatakis AM, Stuber GD. Activation of lateral habenula inputs to the ventral midbrain promotes behavioral avoidance. Nat Neurosci. 2012; 15:1105-1107. [PubMed: 22729176]

Sugam JA, Carelli RM. Rolling the dice: the importance of mesolimbic dopamine signaling in risky decision making. Neuropsychopharmacology. 2013; 38:248. [PubMed: 23147490]

Sugam JA, Day JJ, Wightman RM, Carelli RM. Phasic nucleus accumbens dopamine encodes riskbased decision-making behavior. Biol Psychiatry. 2012; 71:199-205. [PubMed: 22055017]

Toda S, McGinty JF, Kalivas PW. Repeated cocaine administration alters the expression of genes in corticolimbic circuitry after a 3-week withdrawal: a DNA macroarray study. J Neurochem. 2002; 82:1290-1299. [PubMed: 12358776]

Ungless MA, Magill PJ, Bolam JP. Uniform inhibition of dopamine neurons in the ventral tegmental area by aversive stimuli. Science. 2004; 303:2040-2042. [PubMed: 15044807]

Volkow ND, Fowler JS, Wang GJ. The addicted human brain viewed in the light of imaging studies: brain circuits and treatment strategies. Neuropharmacology. 2004; 47(Suppl 1):3-13. [PubMed: 15464121]

Volkow ND, Wang GJ, Fowler JS, Logan J, Gatley SJ, Hitzemann R, Chen AD, Dewey SL, Pappas N. Decreased striatal dopaminergic responsiveness in detoxified cocaine-dependent subjects. Nature. 1997; 386:830-833. [PubMed: 9126741]

Wenzel JM, Waldroup SA, Haber ZM, Su ZI, Ben-Shahar O, Ettenberg A. Effects of lidocaineinduced inactivation of the bed nucleus of the stria terminalis, the central or the basolateral nucleus of the amygdala on the opponent-process actions of self-administered cocaine in rats. Psychopharmacology (Berl). 2011; 217:221-230. [PubMed: 21487661]

West EA, Forcelli PA, Murnen AT, McCue DL, Gale K, Malkova L. Transient inactivation of basolateral amygdala during selective satiation disrupts reinforcer devaluation in rats. Behav Neurosci. 2012; 126:563-574. [PubMed: 22845705] 
Wheeler RA, Aragona BJ, Fuhrmann KA, Jones JL, Day JJ, Cacciapaglia F, Wightman RM, Carelli RM. Cocaine cues drive opposing context-dependent shifts in reward processing and emotional state. Biol Psychiatry. 2011; 69:1067-1074. [PubMed: 21481843]

Wheeler RA, Carelli RM. Dissecting motivational circuitry to understand substance abuse. Neuropharmacology. 2009; 56(Suppl 1):149-159. [PubMed: 18625253]

Wheeler RA, Twining RC, Jones JL, Slater JM, Grigson PS, Carelli RM. Behavioral and electrophysiological indices of negative affect predict cocaine self- administration. Neuron. 2008; 57:774-785. [PubMed: 18341996]

Wightman RM, Heien ML, Wassum KM, Sombers LA, Aragona BJ, Khan AS, Ariansen JL, Cheer JF, Phillips PE, Carelli RM. Dopamine release is heterogeneous within microenvironments of the rat nucleus accumbens. Eur J Neurosci. 2007; 26:2046-2054. [PubMed: 17868375]

Wise RA, Yokel RA, DeWit H. Both positive reinforcement and conditioned aversion from amphetamine and from apomorphine in rats. Science. 1976; 191:1273-1275. [PubMed: 1257748]

Xi ZX, Ramamoorthy S, Shen H, Lake R, Samuvel DJ, Kalivas PW. GABA transmission in the nucleus accumbens is altered after withdrawal from repeated cocaine. J Neurosci. 2003; 23:3498-3505. [PubMed: 12716959] 


\section{Highlights}

- Negative affect and natural reward devaluation are features of drug addiction.

- We review neural mechanisms underlying these processes using a novel rat model.

- Cocaine cues elicit an aversive drug need state and increases motivation for drug.

- Accumbens neurons and rapid dopamine signaling encode this state.

- This research may lead to novel treatments for cocaine addiction 
A

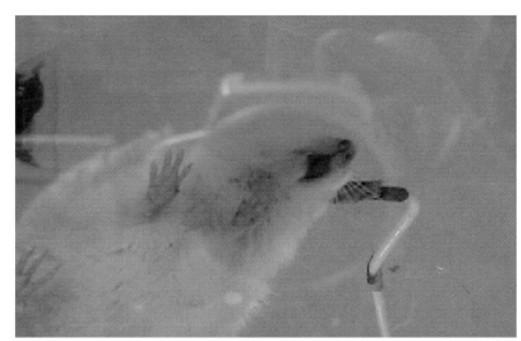

C

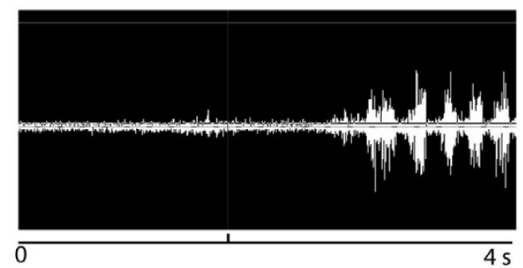

E

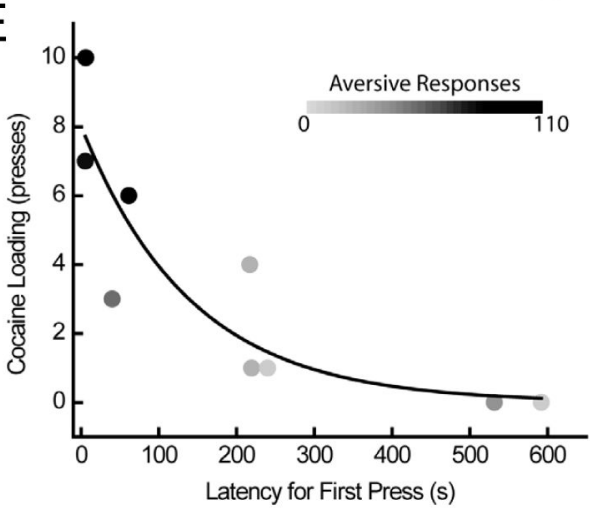

B

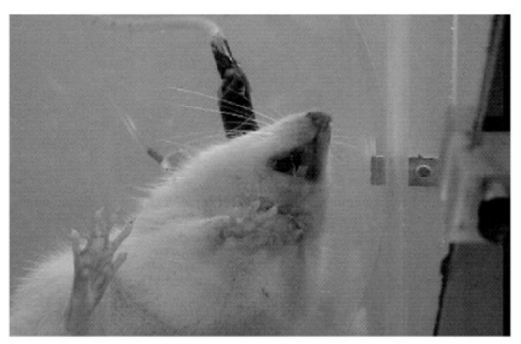

D

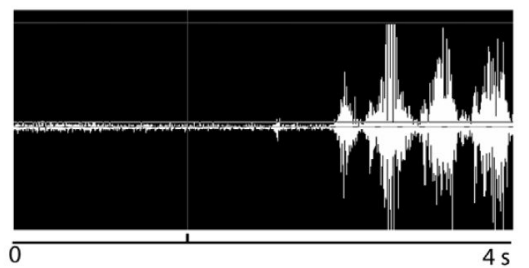

F

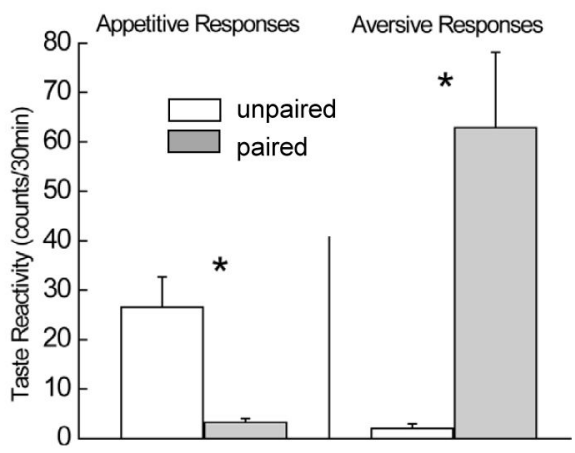

Figure 1.

Behavioral responses to saccharin that predicts delayed cocaine. Before learning, rats exhibit mostly appetitive orofacial reactions to infusion of the saline-paired tastant (A) but aversive reactions to the one paired with impending cocaine (B). Orofacial responses are reflected in EMG activity of the anterior diagastric jaw muscle. EMG activity occurred in rapid, lowamplitude bursts indicative of licking shortly after infusion of the saline-paired tastant (C). These responses occurred during the infusion of the cocaine-paired tastant as well, but longer duration, higher-amplitude contractions indicative of aversive taste reactivity also were observed (D). Cocaine-induced devaluation was correlated with motivation to take cocaine. Drug loading was correlated both to the latency to make the first press and the expression of aversive taste reactivity (plotted in shading, E). Taste reactivity counts (mean \pm SEM) revealed appetitive taste reactivity to the tastant paired with saline and aversive taste reactivity to the one paired with impending cocaine $(\mathrm{F})$. * denotes significant differences, $\mathrm{p}<.05$. Figure modified from Wheeler et al. (2008) with permission from Elsevier. 

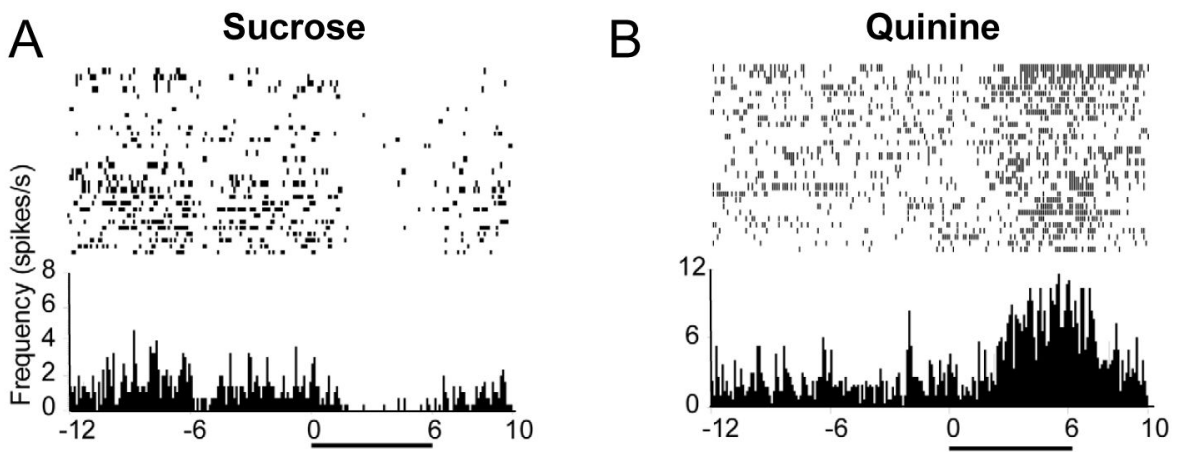

Figure 2.

NAc neurons exhibit opposite firing patterns during intraoral infusion of rewarding versus aversive tastants. Left: raster and perievent histogram $(\mathrm{PEH})$ shows the activity of a representative NAc neuron exhibiting a decrease in firing during infusion of a sweet sucrose solution. Right: another NAc neuron showed increased activity during intraoral infusions of a bitter quinine solution. Pump onset at time 0 in PEH; horizontal black bar indicates intraoral infusion duration. Figure modified from Roitman et al. (2005) with permission from Elsevier. 

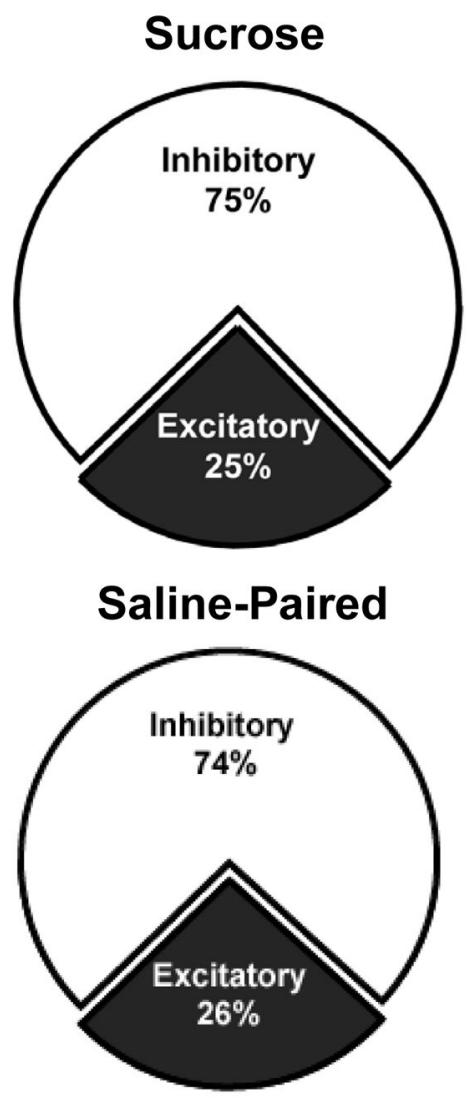

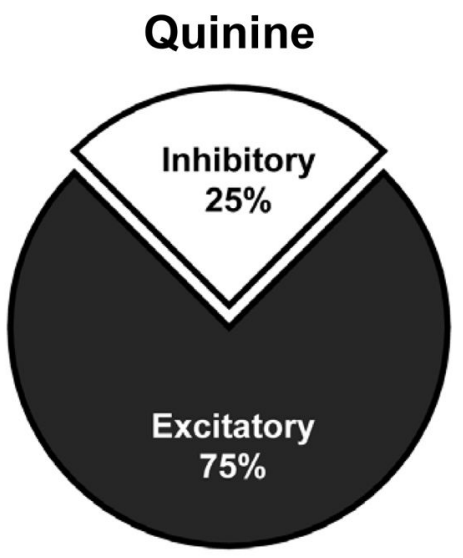

Cocaine-Paired

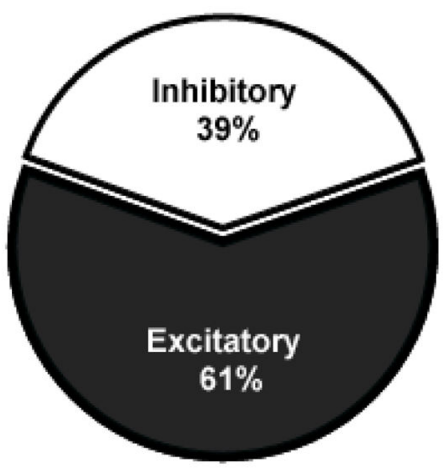

Figure 3.

NAc neurons track the learned aversion to the sweet following its repeated pairing with cocaine. Top: Pie charts showing the distribution of excitatory versus inhibitory neurons during intraoral infusion of a sweet (left) versus quinine (right) in naïve rats. Bottom: The pie charts show that the majority of NAc neurons exhibited inhibitory responses to the tastant paired with saline self-administration (left), but shifted to predominately excitatory activity during infusion of the tastant paired with cocaine self-administration (right). Figure modified from Roitman (2005) and Wheeler et al. (2008) with permission from Elsevier. 

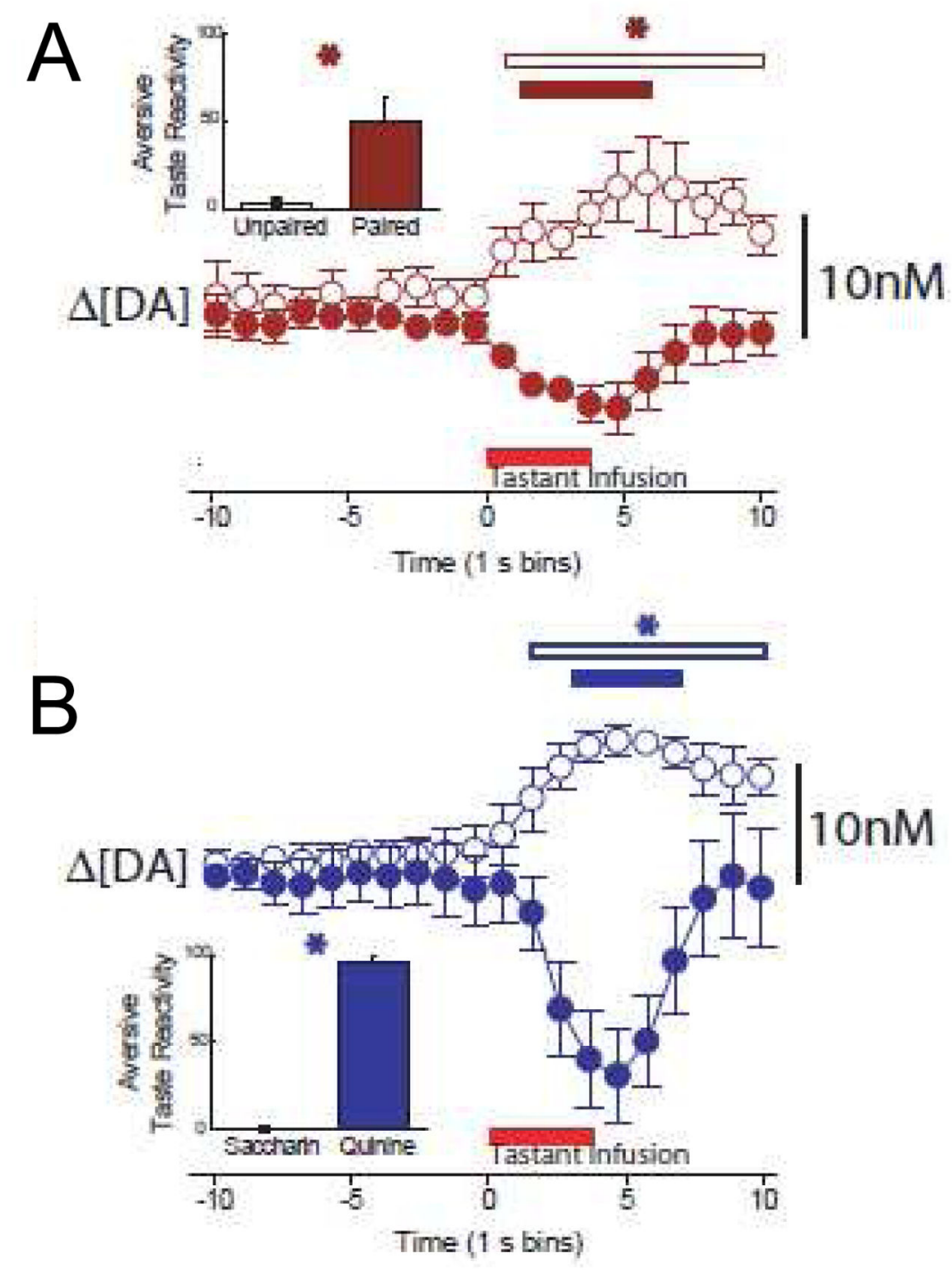

Figure 4.

Aversive conditioning and reduced dopamine release for a cocaine-predictive stimulus. Top: Intraoral infusions of a palatable saccharin solution (unpaired, open circles) elicited dopamine release (mean \pm SEM) whereas a distinctively flavored saccharin solution that predicted a cocaine injection (paired, closed circles) decreased dopamine. Inset: mean counts of aversive taste reactivity were significantly greater for the cocaine-paired compared to the unpaired saccharin solution, $p<.05$. Bottom: Dopamine increased during infusion of saccharin (open circles) and decreased during quinine delivery (closed circles) in naïve rats. Inset: mean counts of aversion were significantly elevated for the quinine solution, not the saccharin solution, $p<.05$. Figure modified from Wheeler et al. (2011) with permission from Elsevier. 

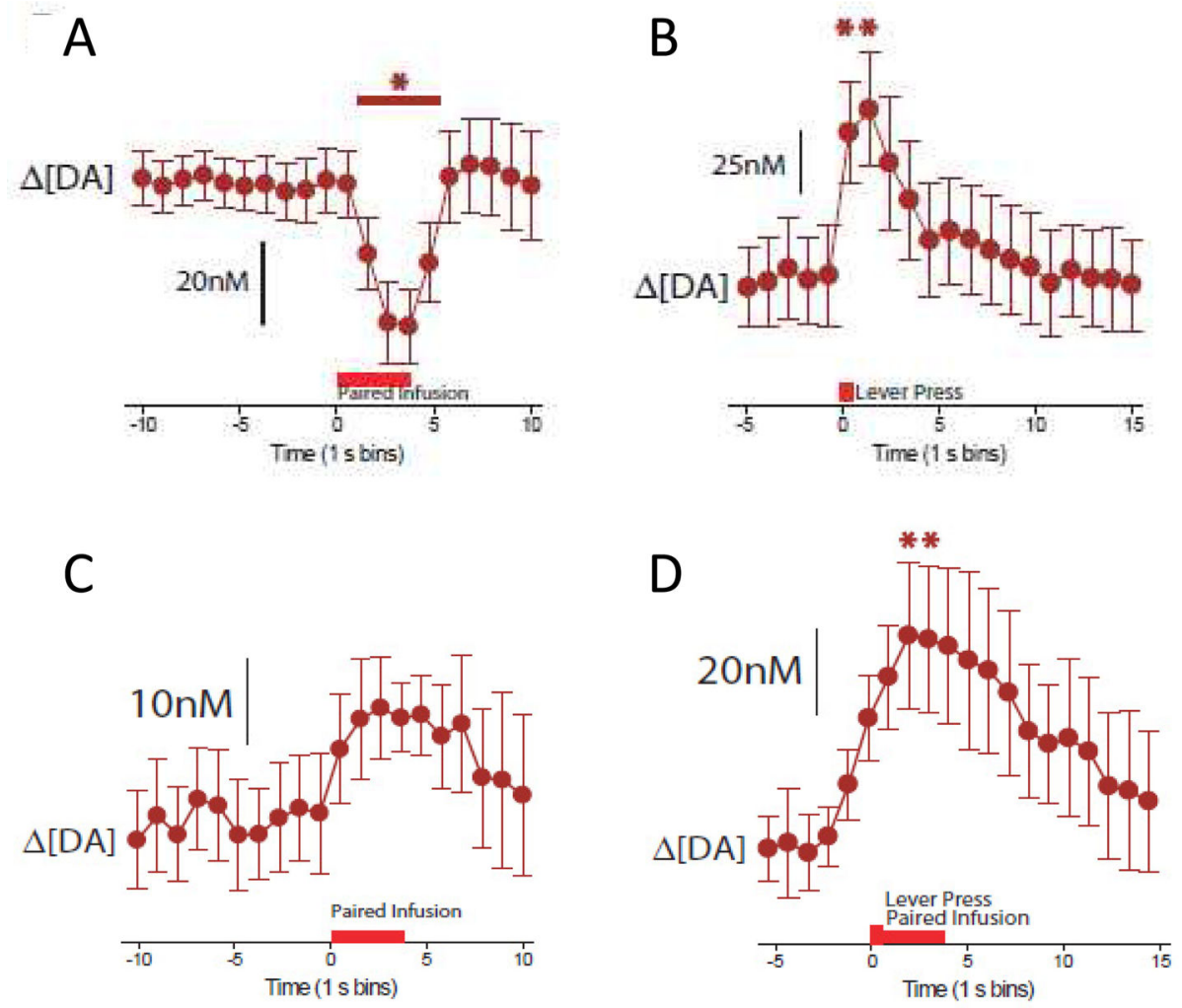

Figure 5.

Dopamine (DA) release during tastant infusion and self-administration. A: Dopamine release to the cocaine-paired audio-visual taste cue before self-administration and, $\mathrm{B}$ : relative to the lever press for cocaine paired with the audio visual cue. C: 'Probe' infusions of the cocaine-paired tastant used instead of the audiovisual cue during self-administration training elevated dopamine concentration across all animals. D: Dopamine release events were also observed immediately following the lever press when the taste cue was used instead of the audiovisual cue during self-administration. *Significant increases in dopamine concentration compared to baseline. Figure modified from Wheeler et al. (2011) with permission from Elsevier. 
A

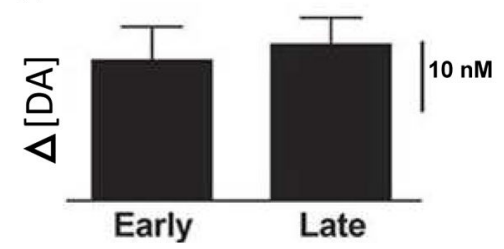

C

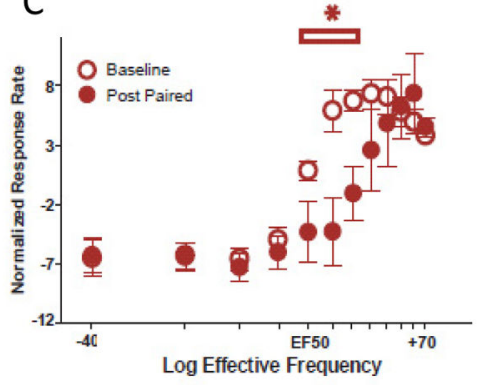

B

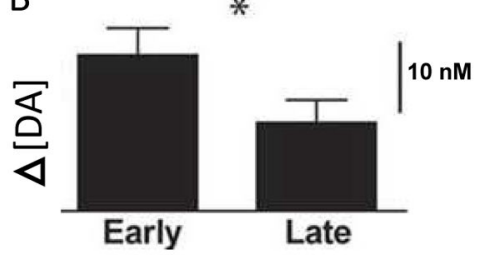

D

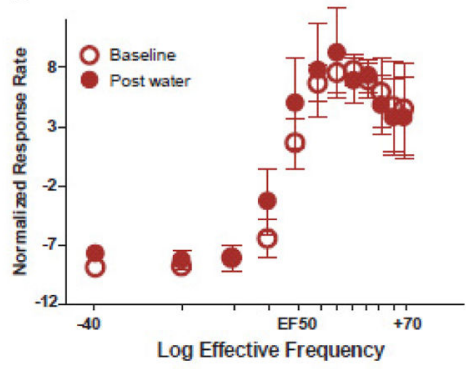

Figure 6.

Dampened dopamine release during the 45-min period before cocaine availability and revealed via ICSS. A: Average dopamine concentration (mean \pm SEM) in the baseline period for all rats receiving the unpaired tastant is stable across trials (early vs. late), $p<.05$. B: Dopamine concentration decreased significantly across trials for rats receiving the cocaine-predictive taste cue. *Significant difference $p<.05$. C: Baseline ICSS threshold curves were established (open circles, mean \pm SEM), then rats received infusions of the cocaine-paired tastant, and the curves were redetermined (closed circles). The cocainepaired tastant right-shifted ICSS thresholds significantly. *Significant differences in ICSS response rates. D: Baseline ICSS threshold curves were established (open circles), and then all rats received infusions of water and the curves were redetermined (closed circles). Water infusions did not change ICSS response rates. Figure modified from Wheeler et al. (2011) with permission from Elsevier. 

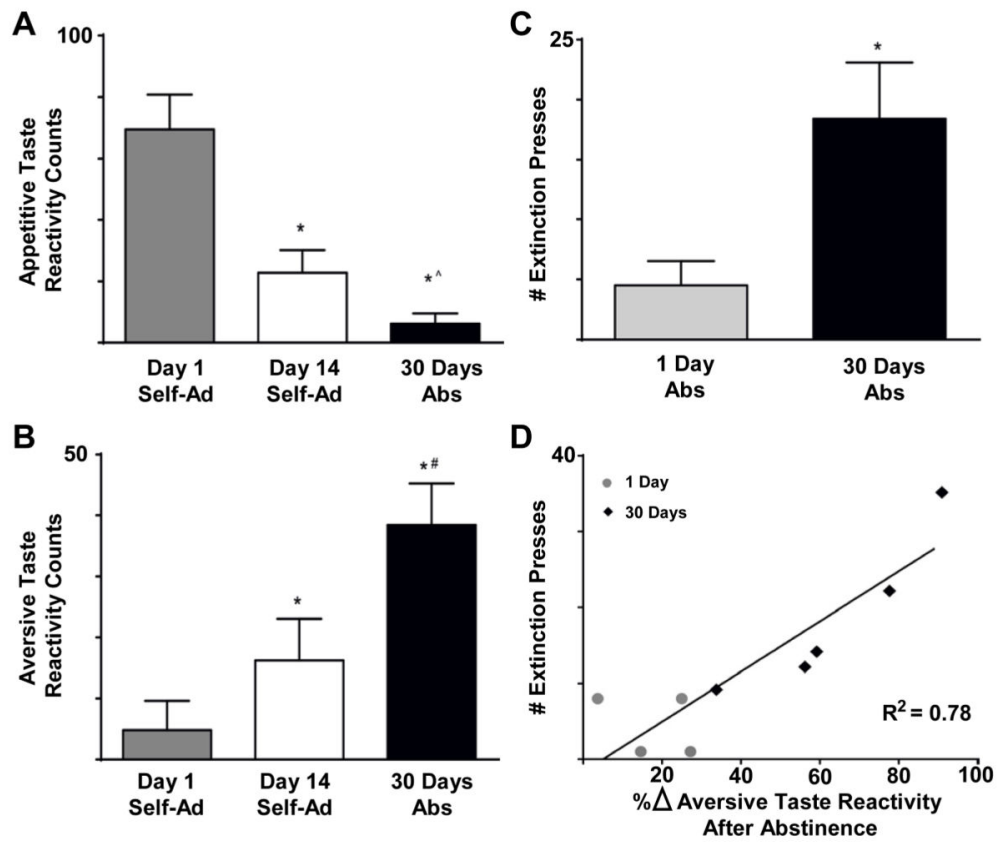

Figure 7.

Abstinence enhances the devaluation of saccharin that predicts impending, but delayed cocaine availability during the first 15 trials of saccharin delivery. On day 1 of training rats exhibited predominantly appetitive taste reactivity counts during saccharin infusion (A\&B, left columns) but aversive counts after saccharin was paired with cocaine for 14 days (A\&B, middle columns). Following 30 days of abstinence, the increase of aversive taste reactivity counts was exacerbated (A\&B, right columns). * denotes significantly different from day 1 , \# denotes significantly different from day $14, \wedge$ denotes a trend towards significantly different from day 14. Experimenter controlled abstinence (30 days) led to an increase in number of lever presses under extinction compared to only 1 day of abstinence (C). * denotes significant difference in lever presses $(\mathrm{p}<0.05)$. The number of lever presses during extinction was positively correlated with the percent change in cocaine-induced devaluation following abstinence (D). 